\title{
A imaginação metafísica na experiência estética da natureza Ronald Hepburn
}

\section{[Metaphysical imagination in aesthetic experience of nature - Ronald Hepburn]}

Maria José Varandas ${ }^{1}$

recebido: $05 / 2014$ aprovado: $10 / 2014$

RESUMO: O artigo expõe a leitura de Ronald Hepburn sobre a apreciação estética da natureza, considerada como a manifestação da imaginação para a suprema síntese. Pressupondo que se trata de uma experiência multidimensional que mobiliza todas as faculdades humanas, o filósofo escocês sublinha a dimensão metafísica dessa experiência que não só potencia o laço entre o ser humano e o mundo natural, como desvela o significado ético e ontológico dessa relação. Neste sentido, a percepção do belo natural constitui uma via de revelação do humano no seu pleno significado.

Palavras-chave: Belo natural; Imaginação Metafísica; Ideais Sintécticos; Sublimidade e Infinito; Liberdade; Estética Ambiental.

ABSTRACT: This paper shows the multi-dimensional aesthetic appreciation of nature on Hepburn's view. His metaphysical imagination model defines the distinctive character of the environmental appreciation and the metaphysical dimension of aesthetic engagement with the natural world. This engagement has an ethical meaning implying the respect and the responsibility for nature. Furthermore, freedom has a major role here promoting an interplay of imagination and practical

1 Centro de Filosofia da Universidade de Lisboa. Mestre em Filosofia, na área de especialização de Filosofia da Natureza e do Ambiente, pela Faculdade de Letras da Universidade de Lisboa; investigadora no Centro de Filosofia da Universidade de Lisboa; presidente da Sociedade de Ética Ambiental. Autora de várias publicações na área da ética e estética ambientais (artigos e livros); conferencista em diversas instituições sobre o tema ambiente. Organizadora e co-organizadora de seminários sobre a temática ambiental. Email- mariajosevarandas1@gmail.com 
consciousness. In this sense, the perception of natural beauty reveals our true humanity.

Key-words: Natural Beauty; Metaphysical Imagination; UnityIdeals; Sublimity and Infinity; Freedom; Environmental Aesthetics.

Se no século XVIII o belo natural detinha um lugar primaz nos textos de estética, na contemporaneidade a Estética ${ }^{2}$ elege como objecto preferencial de teorização o belo artístico circunscrevendo o alcance do seu significado a uma filosofia crítica da arte, numa explícita marginalização do belo natural. Entre as razões explicativas deste assumido desprezo será oportuno apontar a crescente desmistificação do real e a negação de sentido que a sociedade tecnicizada, industrializada e fortemente consumista tem produzido, enquanto derivação da racionalidade instrumental moderna. Como afirma Ronald Hepburn, "o desvanecimento de sentido de que a natureza é nossa 'educadora', de que as suas belezas comunicam mensagens morais mais ou menos específicas" (HEPBURN, 2011, p. 232) conduziu, mãos dadas com a minúcia explicativa da ciência, a uma certa indiferença pela estética natural que, a partir dos anos sessenta do século passado, é fruída, sobretudo, por estratos juvenis new age que recriam uma mitologia da natureza num modismo contra-cultura a maior parte das vezes inconsistente e folclórico. O ressurgimento da exaltação da natureza nessa via underground de tendências hippies (aliás, um

\footnotetext{
${ }^{2}$ Sobre o conceito de Estética e a sua polissemia consulte-se Kirchof (2003) que oferece um panorama detalhado da evolução "fragmentária" do conceito a partir da sua raiz, analisando o seu desenvolvimento no século XVIII (Kant e Baumgarten) e detendo-se nas abordagens contemporâneas vindas da semiótica (Humberto Eco). 
movimento de amplas significações filosóficas, sociológicas e políticas), deveu-se, em larga medida, à evidência da crise ecológica que, simultaneamente, obrigou a uma clara mudança de rumo na reflexão teórica sobre o mundo natural pela consideração dessa realidade "nos seus próprios termos" e indagação do estatuto do ser humano aí, denunciando ainda o antropocentrismo inerente à representação tradicional da relação homem-mundo e reflectido nos diversos domínios da análise filosófica, incluindo a da estética.

Trata-se de um amplo e emergente debate teórico que anuncia uma natureza que se compreende em íntima confinidade com o ser humano e, que por isso, é reconhecida como candidata à consideração moral exigindo dos agentes humanos respeito e responsabilidade. No actual momento, em que a crise ecológica se mostra com um ameaçador potencial de negatividade, esse debate lança os fundamentos de um novo paradigma, o da reconfiguração da relação entre o ser humano e o seu envolvente natural, propondo, em paralelo, modos de superação dos antagonismos que a tradição, desde a modernidade, consagrou homem-natureza; sujeito-objecto; natureza e cultura; estética e ética.

No conjunto de textos seminais que concorrem para uma transfiguração paradigmática das relações do humano com a natureza pontifica o influente e inovador ensaio de Ronald Hepburn "Contemporary Aesthetics and the Neglect of Natural Beauty" (1966), como texto fundador de uma nova via para a estética ao expor a especificidade do belo natural face ao belo 
artístico e ao re-colocar a estética natural no âmbito da reflexão filosófica. Desde logo, a sua interpretação da experiência estética da natureza como abertura à compreensão da natureza e do próprio humano (BROOK, I., 2010, p. 267), revela o distintivo dessa experiência e a sua fundamental significação filosófica, aspectos que virão a ser decisivos na fundação e evolução da estética ambiental. Neste sentido, Hepburn é reconhecido como o autor que devolveu estatuto filosófico à estética natural (tal como Adorno) e considerado, por vários autores, como o 'pai' da estética ambiental.

\section{II}

A assunção de que o modelo de apreciação da arte não pode interpretar a beleza do mundo natural, pois, entre outros aspectos, os objectos naturais são "frameless", ou seja, irredutíveis aos códigos formais que 'emolduram' o objecto artístico, conduz Hepburn à dilucidação do significado da experiência estética da natureza na riqueza infindável dos seus matizes em si mesmos provisórios, fugazes e corrigíveis fruto de incessantes e espontâneos cruzamentos da cognição, da emoção, da razão, da sensibilidade, da imaginação numa contínua circulação entre o plano da realidade física e o plano metafísico, entre a sensorialidade e a abstracção formal, entre o sujeito perceptivo e o natural percebido.

Com a convicção de Rilke de que tudo na natureza nos convida a percebê-la, o filósofo escocês sublinha um dos aspectos fundamentais da estética natural que lhe confere uma inteligibilidade própria contrastante com a apreciação do objecto artístico: a envolvência de mútua implicação, "pela qual o 
espectador se experiencia a si mesmo de uma maneira incomum e vivida, (...), pois estamos na natureza e somos parte $d a$ natureza" (HEPBURN, [1966], 2004, p. 45), o que significa que "não somos meros observadores objectivos" (HEPBURN, 1999b, p. 1), mas antes uma subjectividade plenamente envolvida na realidade contemplada e implicados, por isso, numa relação simbiótica em que a experiência estética surge como uma experiência de co-autoria:

A relação é uma relação simbiótica. É na provisão da natureza que nós exercemos os nossos próprios esforços de ordem perceptual-criativa-imaginativa. A natureza e nós mesmos somos co-autores indissociáveis de, por exemplo, a nossa experiência estética. Pois nós não inventamos os processos da naturezacomo-ela-é-em-si, pelos quais nós- com o nosso distinto aparato perceptual experienciamos a natureza como bela.

HEPBURN, 1999a, p. 20.

Dada a circularidade que encadeia o percepcionante e o percepcionado numa conexão simbiótica, resvalando umas vezes para a humanização do objecto natural e outras para a naturalização do sujeito, como caracterizar a complexidade contextual da experiência do belo natural nas suas diferentes e complementares gradações? "O que é apreciar uma paisagem esteticamente?"

O componente puramente sensório cores, formas, sons, sensações tácteis, cheiros - raramente alguma vez existe por si só. Porque sabemos que aquela extensão de azul é o azul do céu, que aquele disco partido é uma reflexão da luz (...) Nós conceptualizamos, reconhecemos, aduzimos contexto, 
fundo, procuramos afinidades formais de forma reflexiva. (...) Para além de que poderemos não ver simplesmente uma grande e negra nuvem, mesmo acima do horizonte, mas vê-la como um nefasto prenúncio de uma severa tempestade que ameaça o ainda brilhante, mas frágil panorama (...) Aí temos as propriedades expressivas e o pensamento das mudanças ao longo do tempo - até uma uma espécie de drama. (...) Ou, num incisivo contraste, poderemos experienciar a natureza em que a sua pungente beleza, por vezes, parece falar de uma Origem transcendente para a qual nos faltam as palavras e os conceitos claros.

HEPBURN, 2010, p. 1.

Desde impressões concretas até idealizações numinosas há, na percepção estética de um qualquer recorte natural, a confluência das distintas vias de captação do contemplador numa experiência de avassaladora riqueza que convoca o saber conceptual do entendimento, a abertura da sensibilidade à pluralidade de sensações, o impulso da imaginação para uma "certa verdade" que do particular abstrai e metaforiza a suprema síntese ou, o que é o mesmo, a unidade que dá sentido e finalidade ao mistério do existir. A vocação para o transcendente religioso, esse chamamento do Alto, e que olha a natureza como consagração, é o plano cognitivo-emocional de onde brota a imaginação metafísica. Tratar-se-á, segundo Hepburn, do plano culminante de uma experiência estruturada em diversos patamares de realidade e em diferentes modos de leitura que partindo de elementos singulares como rochas, folhas, flores, nuvens tende para formas mais abstractas e gerais de apreender o mundo - o mundo como totalidade e unidade 
(HEPBURN, 2004,p. 57). Na vasta amplitude perceptiva da estética natural, são estabelecidas relações de solidariedade e afinidade entre o percepcionante e o belo contemplado subsumidas em metáforas que respondem aos ideais de unidade (ibid., p. 58) da imaginação e expõem a simbiose entre as duas realidades. O céu, o mar, as nuvens, os bosques, são apreendidas não apenas como realidades belas, mas também como metáforas da condição humana no mundo, uma idealização poética que o romantismo de Wordsworth, a referência tutelar e sempre presente na análise de Hepburn, ilustra de modo exemplar:

How Nature by extrinsic passion first Peopled the mind with forms sublime or fair, And made me love them, may I here omit How other pleasures have been mine, and joys

Of subtler origin; how I have felt,

Not seldom even in that tempestuous time,

Those hallowed and pure motions of the sense

Which seem, in their simplicity, to own An intellectual charm; that calm delight Which, if I err not, surely must belong To those first-born affinities that fit Our new existence to existing things, And, in our dawn of being, constitute The bond of union between life and joy.

Yes, I remember when the changeful earth, And twice five summers on my mind had stamped

The faces of the moving year, even then I held unconscious intercourse with beauty Old as creation, drinking in a pure Organic pleasure from the silver wreaths Of curling mist, or from the level plain Of waters coloured by impending clouds. Wordsworth, Prelude, I, 550. 
Neste caso, o focus imaginarius presente na contemplação estética da natureza desempenha um papel regulador unificando, aparentando e procurando ultrapassar as limitações da finitude e da individualidade no encontro com Alma do Mundo, enquanto expressão significativa da sede de Absoluto cuja irrevogabilidade atesta, ao longo dos tempos e sob múltiplas formas, o ímpeto humano que procura transcender a physis e alcançar o que está para lá, a metaphysis. O paradigma da demanda típico do romantismo de Wordsworth exprime o ensejo de consubstanciação com Deus através da comunhão com a natureza, tendência que, segundo Hepburn, está sempre latente, mais ou menos intensamente, na percepção do belo natural. Reactualizando o legado kantiano e complementando-o com o misticismo da poesia romântica, o nosso autor apresenta a estética natural como uma via ascensional que, da concretude de itens particulares procura desvelar o "insondável véu da natureza" cume que, não esclarecendo, se entreabre à imaginação na sua demanda por fins finais. O filósofo questiona-se sobre as razões que chancelam a imaginação metafísica como um sub-conhecimento identificando essa atitude com uma voluntária e embaraçada fuga ao paradigma romântico wordsworthiano, fuga essa, porventura, derivada da indeterminação da explicação religiosa à qual falta um suporte racional adequado no que tal significa de subordinação à refutabilidade, à demonstração experimental e à coerção lógica. E o nosso autor mostra que esse embaraço não se resolve declarando a experiência estética a salvo da metafísica, uma solução empobrecedora a seu ver, mas antes deve a sua assunção constituir um encorajamento que dá conta 
da riqueza e infinita variedade da estética natural, compreendendo a vocação de infinito que aí se manifesta. Para o autor, esta qualidade intrínseca da apreciação estética da natureza, presente na apreensão do sublime natural, fundamenta a sua convicção de que perspectivar a apreciação do belo natural em termos de uma presumível objectividade decorrente da inteligibilidade científica $^{3}$ seja um caminho que não pode sobrepujar outros modos de interpretação, porquanto a ciência não tem o poder de desalojar a metafísica. Segundo o filósofo, a questão metafísica emerge para além das fronteiras da ciência e tende a procurar suprir a incompletude desta, mediante a complexão ou realização dos processos do mundo no Absoluto, ou Deus. Em consequência, o autor afirma que a interpretação metafísica não substitui a ciência, mas procura delinear o contexto mais amplo no qual a própria ciência evolui; a experiência estética constituirá o nisus entre a explicação científica e o Absoluto, este último a forma de enriquecimento, expansão e elevação da percepção objectiva da realidade que consuma a humana aspiração a uma realidade 'maior', a uma verdade mais 'alta'. Seguramente para Hepburn os aspectos cognitivos sobre a história geológica da região ou sobre a unidade ecológica da fauna e da flora podem bem contribuir para o aprofundamento da experiência estética e, certamente, o farão. Mas, para o autor, a experiência estética não é, nem pode ser dependente da cláusula do entendimento que ofusca ou inibe a perspectiva humana. Uma perspectiva que intui que a natureza é bela e às vezes que a natureza é mais do que somente bela.

\footnotetext{
${ }^{3}$ Tese incluída no cognitivismo estético e destacadamente defendida por Allen Carson (Estética Positiva). Sobre o tema ver AUTOR. 2013a. ÁGORA FILOSÓFICA .v. 1.n. 2 (2014), pp.96-115 e-ISSN 1982-999x
} 
Admitindo como específico da experiência estética a demanda por algo que está fora da concretude espácio-temporal, Hepburn alerta para o risco de sobrevalorização da imaginação metafísica, um outro erro reducionista que prefere valorizar recortes naturais que testemunham a ordem e a perfeição idílicas e desprezam outros - como as áreas selvagens - que não manifestam as características arquetípicas. A polaridade da experiência estética da natureza expõe, sobretudo, um caminho que se desenrola entre o 'baixo' e o 'alto' sem etapas definidas ou roteiros injuntivos, incluindo diversas modalidades de apreciação enquanto expressões multifacetadas da fertilidade imaginativa do sujeito que contempla o belo natural. Assim, num dos pólos o percepcionante satisfaz-se na observação elementar, discernindo qualidades expressivas no próprio momento da percepção, como quando, por exemplo, John Muir (MUIR, 2008) se deleita na contemplação das diferentes formas morfológicas da paisagem por onde vagueia e colhe a satisfação que o exacto momento contemplativo proporciona. Mas quando, a partir daí, o pioneiro ambientalista intui uma unidade transtemporal que subjaz às diferentes configurações observadas, ele situa-se no pólo oposto, aplicando o esquema imaginativo de uma metafísica que apreende e caracteriza o mundo segundo uma transcendente e imensurável escala espácio-temporal. Como se, as anunciações imaginativas de cosmologias metafísicas (teístas ou panteístas, ou até, existencialistasniilistas), fossem lidas no rosto da natureza, constituindo expressões de deleite estético que o sujeito perceptivo procura decifrar. Será esta riqueza pluriforme na apreciação da estética 
natural que explicará a dificuldade da sua conceptualização preceptiva num código consensual:

Existem fortes influências na filosofia britânica contemporânea que incitam a ter a mais completa simpatia para com uma abordagem particularista da beleza natural - como a contemplação de objectos individuais com as suas qualidades perceptivas esteticamente interessantes; e a ter muito pouca simpatia para com a linguagem grandiosa, especulativa e quase mística da "identificação com, ou na natureza". E contudo parece-me que não temos aqui uma abordagem estética boa e uma má, a primeira sensata e a segunda absurda. Ao invés, temos dois pólos ou marcos entre os quais reside uma série de possibilidades estéticas; e no mapeamento desta série tais marcos terão um papel valioso e talvez necessário.

HEPBURN (1966) 2004, p. 49.

É a ampla textura da estética natural que confere à apreciação uma tonalidade viva, dinâmica e sempre renovável, pois, como sublinha Hepburn, qualquer qualidade estética da natureza "É sempre provisória, corrigível por referência a um contexto diferente, talvez mais lato, ou a um outro mais estreito mas percebido com mais pormenor" (ibid., p. 47), característica que impele para "Uma busca por pontos de vista sempre novos e por contextos mais abrangentes".

O 'inquérito' de Hepburn sobre a genuinidade da motivação para mais abrangência que, em última instância, quer "ser-um-com-a-natureza" revela os diferentes graus de intensidade de apreciação convocando uma vezes sobretudo a cognição e outras apelando à imaginação metafísica como via de resgate da morada primeva:

Se temos um sentido de pertença a contextos cada vez mais amplos só pode ser através dessa expansão imaginativa, 
a única instância da qual alguma vez poderemos resgatar o sentido de estar "em casa no universo", pois para muitos de nós tal foi completamente minado pela ciência actual e a perda da crença religiosa teísta.

HEPBURN, 1999b, p.6. Neste sentido, o "mapeamento" das diferentes possibilidades de apreciação da estética natural traçado por Heburn traduz não só o carácter pluriforme da imaginação como também a sua progressão desde patamares predominantemente cognitivos e que operam na concretude espacial até planos de unificação metafísica, a-temporais e a-espaciais. Especificamente:

A unidade com a natureza poderá significar a partilha de propriedades comuns - nós mesmos estamos imersos na paisagem natural e corporeamente conectados com ela. A sensação de afinidade elementar potencia o deleite estético, porque, afinal, "A sua vida [da natureza] é a nossa própria vida: respiramos o seu ar; somos aquecidos e sustentados por um sol comum" (HEPBURN, 2010, p. 7).

Um outro nível de significação revela uma distinguível forma de apreciação estética que 'percebe' analogias entre a vida individual e o que se está a contemplar. Como se os ritmos das formas naturais ressoassem no próprio viver e a contemplação de um mar calmo e azul, por exemplo, com o seu quebrar de ondas sincopado e tranquilo ecoasse no 'eu' como elemento reconciliador e reconfortante. $\mathrm{O}$ deleite que esta experiência induz não é de ordem intelectual, mas estética - "A actividade imaginativa trabalha por um rapprochement entre o espectador e o seu objecto estético: a unidade é de novo uma noção reguladora, um símbolo da inacessibilidade da 
transmutação completa da natureza exterior bruta num espelho da mente" (HEPBURN, 2004, p. 50).

Um modo mais intenso e emocional de experimentar a unidade com a natureza apela para um grau maior de abstracção, percebendo e integrando o ser e a vida individuais no continuum de todas as formas viventes, enquanto configurações efémeras inscritas no ciclo universal que se desenrola entre a vida e a morte (HEPBURN, 2010, p.7).

Por fim, a mais intensa forma de realização do imaginário metafísico é a natureza dos místicos, quando é ultrapassada a distinção sujeito-objecto pela sua imersão numa Realidade Una e Indivisa. O sentido da unidade com a natureza emerge de uma metafísica monista ou panteísta em que tudo é Deus. Exemplos desta plenitude extáctica abundam na literatura nomeadamente a romântica e a sua ressonância nos transcendentalistas do Novo Mundo (cf. AUTOR. 2013b).

A reclamação da dimensão metafísica na experiência estética da natureza convoca em simultâneo a interrogação sobre os sentimentos de respeito e de reverente admiração presentes na contemplação do sublime natural (HEPBURN, 2010, p. 12), paralelo que Hepburn não deixa de notar na meditação sobre o sublime, onde esboça a conjectura da radicação dessa experiência no plano estético-religioso:

O conceito de sublimidade foi concebido como resposta a uma necessidade - a necessidade de nomear o memorável, poderoso e a perplexão de uma experiência (ou de uma série de experiências) de insofismável valor estético, ainda não compreendidas como experiências de beleza pela teoria 
estética neo-clássica. Trata-se de uma experiência que combina o terror perante as esmagadoras energias da natureza e a vastidão do espaço e do tempo, com uma satisfação solene ou entusiasmo. (...) $\mathrm{O}$ entusiasmo era difícil de explicar, e foi explicado de muitos diversos modos, muitos deles envolvendo um componente essencial da imaginação metafísica. A versão de Kant equacionou o medo, o elemento vacilante da imaginação, com a noção da racionalidade própria do sujeito, a autonomia moral, distinta (e incomensurável com) da força bruta da natureza física. (...)

Podemos criticar Burke, por exemplo, por entender o sublime demasiadamente em termos de medo; ou criticar Kant por diminuir o contributo da natureza a favor da sobrevalorização do lado autónomo e racional do sujeito perceptivo.

Sem dúvida de que um modo de lhe conferir sentido (parcial) é o teístico. As esmagadoras magnitudes e energias desafiam a assimilação ao nível dos estímulos sensórios e das sínteses da imaginação, mas são apreendidas como "apontando" para uma Realidade maioralgo cujo mistério e esplendor transluz na experiência. Essencialmente, uma dualidade como a referida por Santo Agostinho: 'et inhorresco et inardesco, (...).

Mas poderemos enveredar pela alternativa (de novo parcial) secular. (...) Estamos atentos não apenas ao desafio sensório e conceptual, mas à possibilidade de ler o carácter -

\footnotetext{
4 «Que luz é esta que me ilumina de quando em quando e me fere o coração sem o lesar? Horrorizo-me e inflamo-me: horrorizo-me enquanto diferente dela, inflamo-me enquanto semelhante a ela», Sto Agostinho, 1984: Livro XI, 9.
} 
expressivo - da estética nos aspectos próprios da natureza que espoletam energias e magnitudes impressionantes, ou mistério.

HEPBURN, 2010, p.10-12.

Embora distintas, as várias teorizações sobre o sublime natural concordam num ponto: o destaque ao factor de imensurabilidade característico da experiência do sublime. A associação da ideia de infinito à experiência do sublime estimula a imaginação metafísica a um perguntar que não se satisfaz com explicações seculares, como testemunha a interrogativa agostiniana, "Que luz é esta?"

O céu estrelado, a vastidão da planície ou do oceano e de outras realidades naturais magnificentes despertam emoções impronunciáveis, perplexidades e interrogações sem respostas óbvias que ecoam na literatura, sobretudo na romântica, como signos de uma poderosa fonte originária de vida e plenitude, esse mistério sagrado que rebelando-se ao conhecimento se descobre no sentir.

Para Hepburn, o sentimento do mistério ou do numinoso que se abriga por detrás da experiência da estética natural emergente em múltiplos momentos contemplativos traduz e manifesta o significado do "mais-do-que-apenas belo", essa impressão frequente e comum que acompanha a contemplação de um aspecto esplêndido da natureza. E, considera o filósofo, não será o conjunto de restrições impostas pela gramática contemporânea da racionalidade a silenciar a tradição mística nessa sua ascese para uma 'verdade mais alta que a verdade' e que, de forma sub-liminar, se introduz na experiência estética. Segundo Hepburn, é indiscutível o conjunto de traços 
impressivos desencadeados pela experiência estética nas suas diferentes versões: um concerto de música pode despertar emoções intraduzíveis pela linguagem e que testemunham uma espécie de ascese do sujeito para regiões extra-ordinárias; também a contemplação de uma árvore ou de uma paisagem natural pode introduzir o sujeito numa totalidade espáciotemporal que é fonte de deleite e entusiasmo. Este sentido da totalidade e unidade extra-ordinárias, segundo o nosso filósofo, é o que, em Rodolph Otto, surge como numinoso, a dimensão do inefável, inacessível à compreensão por conceitos, transbordante e misterioso na vivência e no sentimento da criatura que inspira, em simultâneo, a fascinação e o terror de aniquilamento ( HEPBURN, 1963). Daí que para Hepburn a experiência estética, entendida na sua dimensão metafísica, seja, também, uma experiência de religiosidade, uma experiência de religação do humano com o Absoluto, na qual se consuma e tem lugar o nisus entre uma realidade finita e o infinito. É nessa vivência que se descortina, por vezes, o território a um tempo fascinante e terrífico que vai para além do humano e que inspira respeito e reverência, mas que reflecte, em simultâneo, a humanidade no seu esplendor - liberdade e responsabilidade.

De acordo com Hepburn, a liberdade que caracteriza a experiência estética (tal como Kant "notavelmente" postulou), traz inscrito o nisus para o infinito e coincide com a criatividade inerente a esse exercício do pensamento que busca a conformação do real a sínteses abrangentes e unificadoras. Hepburn exemplifica o exercício pleno da liberdade criativa da imaginação com uma passagem do Sand County Almanac, onde, a partir do espanto pelo espectáculo clamoroso e vibrante dos 
grous, Leopold afirma que o que se ouve não é uma simples ave, mas "a trompeta na orquestra da evolução" (LEOPOLD, [1949], 1966, p. 103). Para Hepburn este tipo de compreensão constitui um triunfo da liberdade imaginativa humana (HEPBURN, 2006, p. 6), buscando, por via do espanto, aceder à verdade ou à verdadeira apreensão do objecto de admiração. Neste

sentido e seguindo as palavras de Isis Brook (2010, p. 267), a experiência estética, tal como é considerada por Heburn, constitui uma abertura para a compreensão do mundo nãohumano e de nós próprios, aí incluindo a nossa liberdade, colocando-nos face a face com a nossa relação com a natureza e com a nossa responsabilidade. Em última instância, "Falar da Natureza é (necessariamente) falar da única e última fonte de todo o desenvolvimento, criatividade, vida consciente e liberdade" (HEPBURN, 1999a, p.18).

\section{III}

No trilho de Kant, Hepburn perspectiva a necessária articulação entre a estética natural e a ética, não só pela fundamental e determinante substrução da liberdade em ambas faculdades, como pela própria condição moral humana timbrada pelo dever e respeito. Se não é possível transferir in toto a postulação kantiana que mandata o respeito entre os seres racionais para as realidades impessoais, a inerência deste sentimento à própria pessoalidade "Recusa encarar a natureza como ilimitadamente explorável, exigindo que compreendamos a fragilidade dos processos e das interdependências ecológicas necessárias a efeitos que nós temos razões para valorizar" (HEPBURN, 1999, p.18). 
Sendo um desses efeitos o belo natural e aquele que mais exemplarmente reflecte a amplitude da subjectividade humana, ele deverá constituir uma vertente indispensável e irredutível do universo axiológico e ético. Neste sentido, sugere Hepburn, a admiração estética associada ao respeito e à compaixão formarão o conjunto (cluster) psico-cognitivo que deve guiar a nossa relação com a natureza (ibid., p. 19).

Dado o exposto, e porque a liberdade inerente à imaginação (cuja riqueza e amplitude reflecte a riqueza e diversidade do mundo natural), se assume como consciência ética na prática, a degradação ambiental, para Hepburn, não constitui apenas uma degradação da natureza, mas sobretudo a degradação das fundamentais faculdades humanas:

Assim endurecendo-nos a nós mesmos, tornando-nos menos sensíveis à degradação ambiental (...) soa vergonhosamente a algo como tentar vermo-nos livres da nossa má consciência, porque a consciência como tal foi cirurgicamente removida. HEPBURN, 1999b, p. 12.

\section{REFERÊNCIAS BIBLIOGRÁFICAS}

BRADY, E., 2003, Aesthetics of the natural environment, Edinburgh: Edinburgh University Press, Ltd

BROOK, I. 2010 (August). Ronald Hepburn and the Humanising of Environmental Aesthetics. In Environmental Values, 19: 3, The White Horse Press, pp 265-271; disponível on-line em: http://dx.doi.org/10.3197/096327110X519826 (acess. Dezembro 2012).

HEPBURN, R. W. 1963. From World to God. In Mind, New Series, vol. 72, n 285, Jan., Oxford University Press, pp 40-50. HEPBURN, R. 1966. Contemporary Aesthetics and the Neglect of Natural Beauty. In British Analytical Philosophy. B. Williams 
and A. Montefiori (eds.) London: Routledge \& Paul Kegan, pp. 285-310. 2004. In Allen Carlson and Arnold Berleant (eds.), The Aesthetics of Natural Environments, Ontario: Broadview Press, pp. 43-62. Versão portuguesa: 2011. A estética contemporânea e o desprezo pela beleza natural. Trad. Tiago Carvalho in Serrão, A. V. (coord.), Filosofia da Paisagem, uma Antologia, Lisboa: CFUL, pp 230-255.

HEPBURN, R. 1999a. Values and Cosmic Imagination. In The Nordic Journal of Aesthetics, vol.11: 19, Nordic Society of Aesthetics, pp. 5-21; disponível on-line: http://ojs.statsbiblioteket.dk/index.php/nja/article/view/3153/269 7 (acess. Dez. 2012).

HEPBURN, R. 1999b. Knowing (Aesthetically) Where I Am. Lancaster University: Dept. of Philosophy, pp 1-13; disponível on-line em:

http://www.lancs.ac.uk/users/philosophy/awaymave/onlineresou rces/hepburn.pdf (ac. Dez. 2012).

HEPBURN, R. 2006 (April). Freedom and Receptivity in Aesthetic Experience. In Postgraduate Journal of Aesthetics. Vol. 3, n 1. British Society of Aesthetics (ed.), pp 1-14.

HEPBURN, R., 2010. Landscape and the Metaphysical Imagination. In Landscapes, Themes in Environmental History, Cambridge: The White Horse Press, pp 1-14.

KIRCHOF, E. 2003. Estética e Semiótica, de Baumgarten e Kant a Umberto Eco. Porto Alegre: EDIPUCRS.

LEOPOLD, A. 1949. A Sand County Almanac and Sketches Here and There. New York: Oxford University Press. 1966. A 
Sand County Almanac, With Essays on Conservation from Round River. N. York: Ballantine Books MUIR, J. 2008. A Near View of the High Sierra. In Carlson, Allen, and Lintott, Sheila (eds), Nature Aesthetics and Environmentalism, From Beauty to Duty. New York: Columbia Press University, pp 64-75

SANTO AGOSTINHO. 1984. Confissões. Tradução J. Oliveira Santos e A. Ambrósio de Pina, Porto: Livraria Apostolado da Imprensa.

VARANDAS, M. J. 2013a (Dezembro). Allen Carlson, Natureza e Estética Positiva. In Kairos, Revista de Filosofia e Ciência 8. Lisboa: Faculdade de Ciências da Universidade de Lisboa. On linehttp://kairos.fc.ul.pt/nr\%208/Allen\%20Carlson\%20Natureza\%2 0e\%20Estetica\%20Positiva.pdf VARANDAS, M. J. 2013b. As Raízes Europeias do Ambientalismo, Rousseau no Novo Mundo. Revista Perspectiva Filosófica. Vol. 1, n. 39. UFPE. Disponível on-line: http://www.revista.ufpe.br/revistaperspectivafilosofica/index.ph p/revistaperspectivafilosofica/issue/current

WORDSWORTH, Prelude, I, 550. On- line: http://www.bartleby.com/145/ww287.html (acess. Outubro 2012) 